\title{
Removal of S6K1 and S6K2 leads to divergent alterations in learning, memory, and synaptic plasticity
}

\author{
Marcia D. Antion, ${ }^{1}$ Maayan Merhav, ${ }^{2}$ Charles A. Hoeffer, ${ }^{3,4}$ Gerald Reis, ${ }^{5}$ \\ Sara C. Kozma, ${ }^{6}$ George Thomas, ${ }^{6}$ Erin M. Schuman, ${ }^{5}$ Kobi Rosenblum, ${ }^{2}$ \\ and Eric Klann 1,3,4,7
}

${ }^{7}$ Department of Neuroscience, Baylor College of Medicine, Houston, Texas 77030, USA; ${ }^{2}$ Center for Brain and Behavior, Department of Neurobiology and Ethology, University of Haifa, Haifa 30905, Israel; ${ }^{3}$ Center for Neural Science, New York University, New York, New York 10003, USA; ${ }^{4}$ Department of Molecular Physiology, California Institute of Technology, Howard Hughes Medical Institute, Pasadena, California 91125, USA; ${ }^{5}$ Division of Biology, California Institute of Technology, Howard Hughes Medical Institute, Pasadena, California 91125, USA; ${ }^{6}$ Department of Genome Science, Genome Research Institute, University of Cincinnati, Cincinnati, Ohio 45237, USA

\begin{abstract}
Protein synthesis is required for the expression of enduring memories and long-lasting synaptic plasticity. During cellular proliferation and growth, S6 kinases (S6Ks) are activated and coordinate the synthesis of de novo proteins. We hypothesized that protein synthesis mediated by S6Ks is critical for the manifestation of learning, memory, and synaptic plasticity. We have tested this hypothesis with genetically engineered mice deficient for either S6K1 or S6K2. We have found that S6K1-deficient mice express an early-onset contextual fear memory deficit within one hour of training, a deficit in conditioned taste aversion (CTA), impaired Morris water maze acquisition, and hypoactive exploratory behavior. In contrast, S6K2-deficient mice exhibit decreased contextual fear memory seven days after training, a reduction in latent inhibition of CTA, and normal spatial learning in the Morris water maze. Surprisingly, neither S6K1- nor S6K2-deficient mice exhibited alterations in protein synthesis-dependent late-phase long-term potentiation (L-LTP). However, removal of S6K1, but not S6K2, compromised early-phase LTP expression. Furthermore, we observed that S6K1-deficient mice have elevated basal levels of Akt phosphorylation, which is further elevated following induction of L-LTP. Taken together, our findings demonstrate that removal of S6K1 leads to a distinct array of behavioral and synaptic plasticity phenotypes that are not mirrored by the removal of S6K2. Our observations suggest that neither gene by itself is required for L-LTP but instead may be required for other types of synaptic plasticity required for cognitive processing.
\end{abstract}

Protein synthesis is required for multiple learning tasks as well as multiple forms of synaptic plasticity (Davis and Squire 1984; Frey et al. 1988; Rosenblum et al. 1993; Kang and Schuman 1996; Manahan-Vaughan et al. 2000). S6 kinase (S6K) activity is known to be correlated with enhanced protein synthesis (Dufner and Thomas 1999). The S6Ks were initially implicated in the translation of mRNAs containing a 5' oligopyrimidine tract (5'TOP), which encode for components of the translational apparatus and promote ribosome biogenesis (Ferrari and Thomas 1994; Jefferies et al. 1994; Meyuhas 2000). However, translation of 5'TOP mRNAs still occurs in mutant mice lacking both S6K genes (Pende et al. 2004), and emerging studies support alternative translational control functions for these kinases (Ruvinsky et al. 2005; Ruvinsky and Meyuhas 2006). Recent work suggests that the S6Ks are critical for the formation of the protein synthesis preinitiation complex (PIC) on eukaryotic mRNA (Holz et al. 2005). Phosphorylated ribosomal protein S6, a direct substrate of S6Ks, can be recruited to the 7-methylguanosine cap-binding complex, suggesting a direct role in translational control (Roux et al. 2007). In addition, direct substrates of S6K that similarly promote enhanced protein synthesis have been identified, including eukaryotic initiation factor 4B (eIF4B), an RNA helicase promot-

${ }^{7}$ Corresponding author.

E-mail eklann@cns.nyu.edu; fax (212) 995-4011.

Article is online at http://www.learnmem.org/cgi/doi/10.1101/lm.661908. ing factor (Raught et al. 2004); eukaryotic elongation factor 2 kinase, a regulator of peptide chain elongation (Wang et al. 2001); and programmed cell death protein 4 (PDCD4), a protein that regulates the levels of the helicase eukaryotic initiation factor 4A (eIF4A) (Dorrello et al. 2006).

In mammals, there are two genes that encode for the S6Ks, S6K1 and S6K2, with each represented by two protein isoforms: S6K1S and S6K1L (often referred to as p70S6K and p85S6K), and S6K2S and S6K2L (Um et al. 2006). To date, the S6Ks appear to be regulated in a similar fashion by mammalian target of rapamycin (mTOR) and phosphoinositide-dependent protein kinase 1 (PDK1) (Um et al. 2006). In the hippocampus, other upstream mediators of S6K1/2 activation include the class 1 phosphoinositide 3-kinase (PI3K) and extracellular signal-regulated protein kinase (ERK) signaling pathways, both of which are each required for protein synthesis-dependent late-phase LTP (L-LTP) (Raymond et al. 2002; Sanna et al. 2002; Tang et al. 2002; Alarcon et al. 2004; Kelleher et al. 2004; Banko et al. 2005; Tsokas et al. 2005 , 2007). Interestingly, activation of S6K1 has been shown to occur after either stimulation of neurotransmitter receptors or induction of protein synthesis-dependent LTP, and in some cases, the dynamic localization of activated S6Ks to specific areas of dendritic spines has been observed (Cammalleri et al. 2003; Francesconi et al. 2004; Lenz and Avruch 2005; Tsokas et al. 2005, 2007; Gonzalez-Mejia et al. 2006; Page et al. 2006). It also is known that phosphorylation of ribosomal protein S6 and syn- 
thesis of the 5'TOP-encoded proteins elongation factor $1 \mathrm{~A}$, elongation factor 2, polyadenylation binding protein, and S6 itself occur shortly after the induction of LTP (Kelleher et al. 2004; Tsokas et al. 2005, 2007).

Thus, multiple lines of evidence support a potential role for the S6Ks to be uniquely involved in synaptic plasticity and, hence, learning and memory. Consistent with this hypothesis, contextual fear memory training results in enhanced S6 phosphorylation (Kelleher et al. 2004). Moreover, mTOR, PI3K, and ERK inhibitors, each of which decrease S6K activation, are known to inhibit the expression of associative fear memory and the retention of spatial learning (Atkins et al. 1998; Selcher et al. 1999; Chen et al. 2005; Bekinschtein et al. 2006; Dash et al. 2006; Horwood et al. 2006; Parsons et al. 2006). Last, phosphorylation of S6K1 is enhanced in several brain regions following training for several memory tasks (Belelovsky et al. 2005; Bekinschtein et al. 2006; Dash et al. 2006; Parsons et al. 2006).

To determine the contribution of S6Ks in cognitive processes, we have utilized genetically engineered mice deficient for either S6K1 or S6K2 and measured their performance in multiple learning and memory tasks. We also analyzed different forms of synaptic plasticity in the S6K1- and S6K2-deficient mice. Our results indicate that there are selective impairments in learning, memory, and hippocampal synaptic plasticity that are unique to the removal of each S6K gene. These studies demonstrate that S6K1 and S6K2 differentially contribute toward the normal expression of behavioral learning and hippocampal synaptic plasticity.

\section{Results}

Pavlovian fear conditioning that consists of pairing a noxious stimulus (foot shock, US) to a conditioning stimulus (auditory cue, CS) results in the formation of long-term fear memory after a single training trial. Infusion of protein synthesis inhibitors before and after training results in selective deficits in the expression of fear memory in rodents (for review, see Klann and Dever 2004). This suggests that if S6 kinases participate in protein synthesis, mice with a genetic deletion of either S6K1 or S6K2 are likely to have deficits in the expression of fear memories. Therefore, we initially assessed the performance of either S6K1- or S6K2-deficient mice in associative fear conditioning. Fear behavior measured during training of either genotype of S6K mouse was found to be comparable with that of wild-type mice during the initial exploration of the chamber and exposure to the first cue-shock pairing. This demonstrates that the S6K-deficient mice express similar behaviors during brief exploration of the chamber and are able to respond to painful experiences (Fig. 1A,B). A mild deficit in the expression of fear behavior was apparent after the last cue-shock pairing during the training session (Fig. 1A,B). This deficit was not likely to result from a decrease in pain sensitivity because, when tested for foot shock pain threshold, the S6K-deficient mice displayed similar responses to wild-type mice (data not shown). The mild decrease in the response of both S6K1- and S6K2-deficient mice during the last cue-shock pairing suggests that they have a mild acquisitional learning impairment in this associative task. The mice then were tested for the retention of contextual information (context test) over time by placing them back into the conditioning chamber one hour, one day, or seven days after training. We observed that S6K1-deficient mice exhibited a reduction in contextual fear memory measured as early as one hour after training (Fig. 1C). In contrast, S6K2 knockout mice exhibited a deficit in contextual fear memory seven days after training compared with that of wild-type littermates, whose freezing increased from day one (Fig. 1D). The absence of the improved performance in contextual fear memory by S6K2-deficient mice suggests they have a deficit in long-term memory consolidation. In these tasks, similar context-specific fear impairments were found in S6K1 and S6K2 heterozygous knockout mice (data not shown), indicating that full expression of either of these genes is required for adequate memory formation. In contrast with the impairments in contextual fear memory, freezing of the S6K1- and S6K2-deficient mice was comparable with wild-type mice during the presentation of the auditory cue two hours, one day, or seven days after training (Fig. 1C,D). Importantly, the performance of the S6K1- and S6K2deficient mice during the presentation of the auditory cue was indistinguishable from that of wild-type mice, demonstrating that S6K1- and S6K2-deficient mice were able to properly acquire and express learned fear. Thus, S6K1 and S6K2 are required for the acquisition and consolidation of normal contextual, but not cued, fear memory.

Alterations in protein synthesis signaling molecules have been observed in the insular cortex within 20 min of novelty taste learning (Belelovsky et al. 2005). Coincident with this finding, marked increases in the phosphorylation of S6K isoforms were shown to occur in association with taste learning (Belelovsky et al. 2005). These findings suggested that the deletion of S6K isoforms might alter the expression of taste memory. To examine this possibility, S6K null mice were exposed to a novel liquid taste $(0.5 \%$ saccharin) that was paired one hour later with $\mathrm{LiCl}$ injection to induce mild illness in the conditioned taste
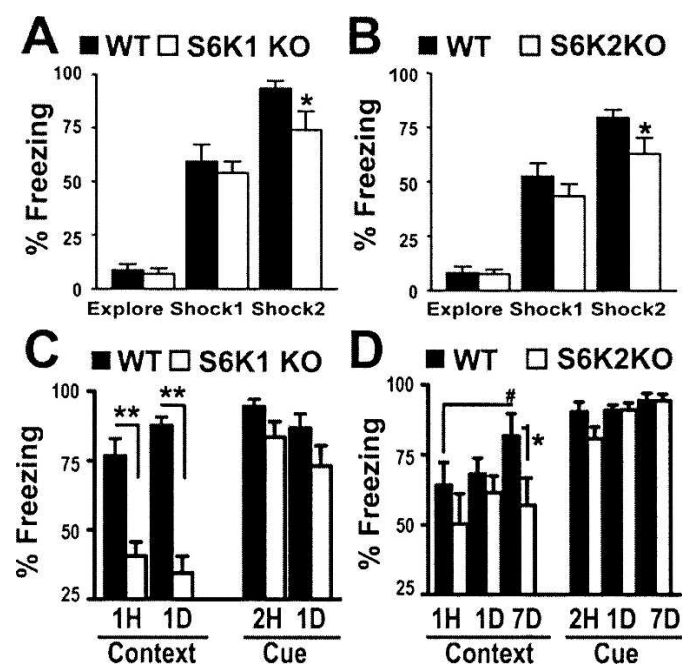

Figure 1. S6K knockout mice exhibit context-specific associative fear memory deficits. $(A, B)$ S6K1 knockout $(\mathrm{KO})(A)$, S6K2 KO $(B)$, and wildtype (WT) mice show similar behavior responses during a 3-min exposure to the training box (Explore) and 2 min after the first cue-shock pairing (Shock1). Two min after the second cue-shock pairing (Shock2), S6K1 $\mathrm{KO}$ and S6K2 KO mice achieve subthreshold maximal freezing behavior compared with WT mice (Shock2: S6K1 WT: $94 \pm 4 \%, \mathrm{n}=24 ;$ S6K1 KO: $74 \pm 9 \%, \mathrm{n}=22$; S6K2 WT: $83 \pm 4 \%, \mathrm{n}=31$; S6K2 KO: $63 \pm 7 \%$, $\mathrm{n}=29$ ). (C) S6K1 KO mice show less fear memory one hour $(1 \mathrm{H})$ and one day (1D) following training during the context test $(1 \mathrm{H}$ : $\mathrm{WT}=77 \pm 6 \%$, $\mathrm{n}=12 ; \mathrm{S} 6 \mathrm{~K} 1 \mathrm{KO}=41 \pm 5 \%, \mathrm{n}=12 ; 1 \mathrm{D}: \mathrm{WT}=88 \pm 12 \%, \mathrm{n}=12 ; \mathrm{S} 6 \mathrm{~K} 1$ $\mathrm{KO}=35 \pm 6 \%, \mathrm{n}=12$ ) and normal memory for the auditory cue. $(D)$ S6K2 KO mice exhibit a mild deficit expressed seven days (7D) after training in the context test. This apparent deficit may reflect an improvement in the performance of WT mice that is not observed in S6K2 KO mice (1D: WT $=68 \pm 6 \%, \mathrm{n}=18 ; \mathrm{S} 6 \mathrm{~K} 2 \mathrm{KO}=62 \pm 6 ; 7 \mathrm{D}$ : $\mathrm{WT}=82 \pm 8 \%, \mathrm{n}=18$; S6K2 KO $=57 \pm 10 \%, \mathrm{n}=7$ ). Normal memory was observed in S6K2 KO mice for the auditory cue. Interestingly, S6K1 and S6K2 heterozygous KO mice also exhibited contextual fear memory deficits comparable with those observed in S6K1 KO and S6K2 KO mice (data not shown). (**, $P<0.001$ and ${ }^{*}, P<0.05$ compared with WT littermate mice at the same time point. \#, $P<0.05$ compared with performance of WT mice at $1 \mathrm{~h}$. Statistics calculated with a Student's $t$-test.) 
aversion (CTA) task. During conditioning, S6K1- and S6K2deficient mice consumed similar amounts of the novel taste as compared with wild-type mice, indicating that taste consumption was normal (Fig. 2A,B). However, S6K1-deficient mice displayed a lower aversion index to novel taste paired with $\mathrm{LiCl}$ (Fig. 2C). To test the strength of aversive memory, S6K1-deficient mice were re-exposed to the novel taste for multiple sessions. The extinction curve measured indicated that aversive taste memory was fragile in the S6K1 knockout mice (Fig. 2D). To ensure that S6K1-deficient mice maintain normal gustatory responses and are able to express taste aversion, quinine, a normally aversive taste, was presented over multiple trials. S6K1 knockout mice had an aversion index to quinine that was comparable with that of wild-type mice (data not shown). In contrast to the robust deficit in S6K1 null mice, S6K2 null mice displayed normal taste aversion after CTA (Fig. 2E). However, pre-exposure of the novel taste (latent inhibition [LI]), which results in a substantial reduction of aversion in wild-type mice, did not alter aversion in the S6K2deficient mice (Fig. 2E). This finding suggests that S6K2 is required for long-term memory of a novel taste experience. Taken together, these results demonstrate that $\mathrm{S} 6 \mathrm{~K} 1$ and $\mathrm{S} 6 \mathrm{~K} 2$ are each uniquely necessary for normal associative taste learning.

Spatial learning is a complex behavior that requires multimodal sensory processing, relies primarily on the hippocampus, and requires protein synthesis for normal performance. To test the possible contribution of S6K isoforms specifically in spatial learning, S6K1 and S6K2 null mice were trained in the Morris water maze task. During Morris water maze training, S6K1- and S6K2-deficient mice achieved similar latencies over a span of seven days (Fig. 3A,B). On the third and seventh days of training, the platform was removed, and the mice were given a probe trial by measuring their search patterns. S6K1- and S6K2-deficient mice exhibited similar preferences for the target quadrant of the pool that previously contained the platform (Fig. 3C,D). Spatial selectivity also was measured by the number of crossings and time spent at the exact location of the platform. S6K1-deficient mice made fewer platform crossings and spent less time at the precise target location on day three, but this impairment was not detected by day seven (Fig. 3E,F). In contrast, S6K2-deficient mice performed comparably with wild-type mice during both probe trials (Fig. 3G,H). S6K1 null mice maintained a swim speed of $\sim 90 \%$ of control mice during a 60 -sec swim test (Fig. 3I). Despite this mild deficit, S6K1-deficient mice performed similarly to their wild-type counterparts in a visible platform version of the water maze (Fig. 3J) and achieved normal performance during training (Fig. 3A). S6K2-deficient mice maintained normal swim speed (Fig. 3K) and performed well in the visible platform task (Fig. 3L). Together, these findings indicate that S6K1 is required for the optimal acquisition of accurate spatial learning, whereas S6K2 is not required for spatial learning in the Morris water maze task.

Because exploratory behavior, motor function, and anxiety can impact the performance of mice during the associative learning tasks, basic measures of these parameters were conducted. S6K1- and S6K2-deficient mice were characterized for motor activity and anxiety in the open field task. In this test, mice explore a brightly lit box for a period of 30 min while their movements are measured with the automated capture of laser beam breaks. In general, most mice explore the box with a rich repertoire of vertical and horizontal movements, head rearing, and occasional stereotypic behaviors (such as grooming). We observed that S6K1 knockout mice were remarkably hypoactive in this task. The number of horizontal and vertical movements, the duration of each movement, and the total distance traveled was significantly less in S6K1-deficient mice compared with wild-type littermates (Table 1). Another aspect of this behavioral task is to determine gross levels of anxiety, because it is known that mice with exag-
A

B
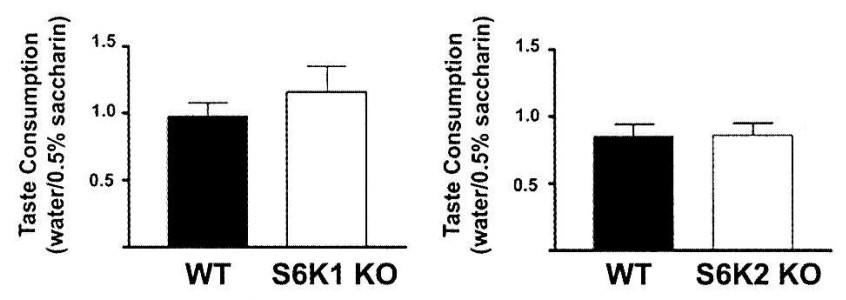

C
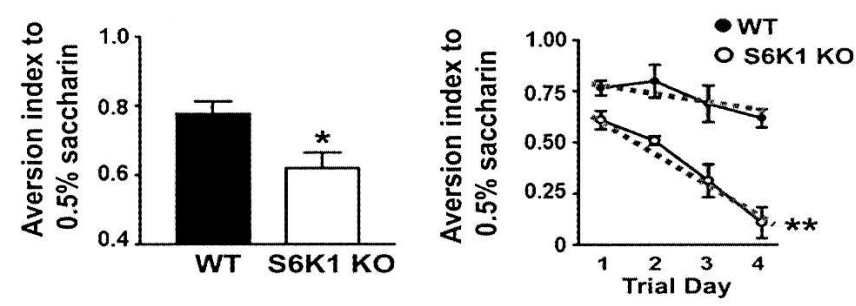

E

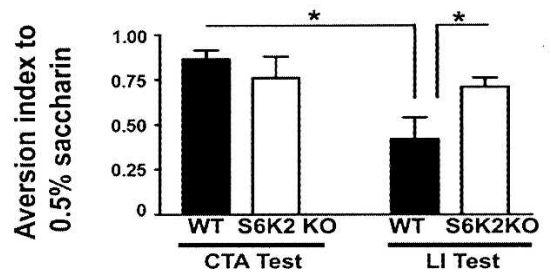

Figure 2. S6K knockout mice have deficits in taste learning. (A) The ratio of water $/ 0.5 \%$ saccharin consumed during novel taste training was comparable between the S6K1 knockout (KO) and wild type (WT) (S6K1 KO: $1.158 \pm 0.197, \mathrm{n}=5$; WT: $0.972 \pm 0.107, \mathrm{n}=7$; t-test; $P=0.529$ ). (B) Similarly, this ratio was not different between S6K2 KO and wild type (S6K2 KO: $0.859 \pm 0.092, \mathrm{n}=7$; WT: $0.848 \pm 0.087, \mathrm{n}=7$; t-test; $P=0.096)$. (C) S6K1 knockout mice show less aversion than wild-type mice to a novel taste $(0.5 \%$ saccharin) that was paired with $\mathrm{LiCl}$ $(\mathrm{WT}=0.78 \pm 0.04, \mathrm{n}=5$; S6K1 KO $=0.62 \pm 0.05, \mathrm{n}=7)$. (D) Extinction training over four days reveals that $56 \mathrm{~K} 1 \mathrm{KO}$ mice do not maintain taste aversion to the same degree as WT mice (coefficient of extinction: $\mathrm{WT}=-0.07 \pm 0.03 ; \mathrm{S} 6 \mathrm{~K} 1 \mathrm{KO}=-0.18 \pm 0.02$ ). However, S6K1 KO mice were able to express natural aversion to $0.04 \%$ quinine, demonstrating that gustatory responses are intact (data not shown). (E) S6K2 KO mice exhibit normal taste aversion (CTA test: WT $=0.86 \pm 0.05, \mathrm{n}=5$; S6K2 $\mathrm{KO}=0.77 \pm 0.11, \mathrm{n}=5$ ). However, two pre-exposures to the novel taste prior to the CTA training session revealed that S6K2 KO mice maintain a high aversion index (latent-inhibition, LI-right) whereas WT mice do not (LI test: $\mathrm{WT}=0.42 \pm 0.10, \mathrm{n}=7 ; \mathrm{S} 6 \mathrm{~K} 2 \mathrm{KO}=0.71 \pm 0.04$, $\mathrm{n}=7) .\left({ }^{*}, P<0.05\right.$ compared with WT littermates with a Student's $t$-test).

gerated anxiety will spend significantly less time in the bright center of the box versus the less luminous periphery. We found that S6K1 mutant mice displayed normal anxiety levels, as the ratio of time spent in the center versus the periphery was comparable with that of wild-type littermates (Table 1). In contrast to these findings, S6K2 null mice were normal in all the tasks measured (Table 1). To determine whether the deficit in exploratory behavior in S6K1 null mice was the result of either a physical motor impairment or a lack of motivational interest, we further measured motor coordination and ability with the rotating rod task. In this task, mice were placed onto an accelerating rotating rod, and latency to fall was measured over successive trials. All of the mice displayed similar learning curves over the span of eight trials (Table 1). These results indicate that when S6K1-deficient mice are challenged, they are capable of normal motor learning and performance. 
A

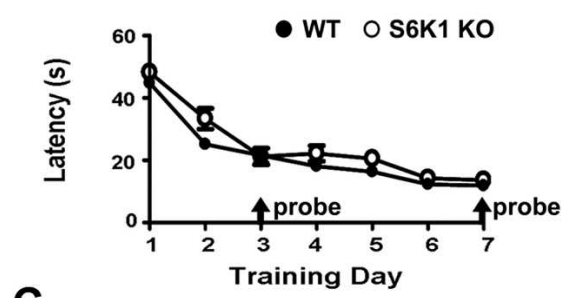

C

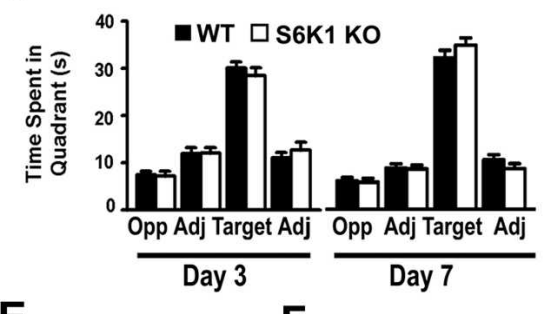

E

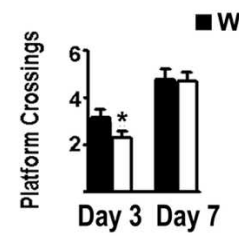

-WT $\square$ S6K1 KO

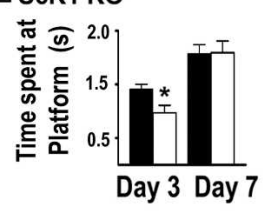

I
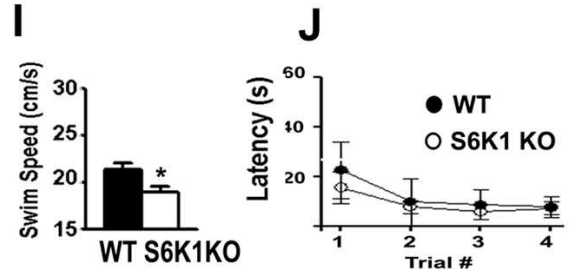

B

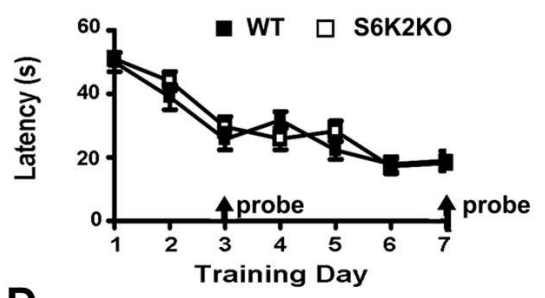

D
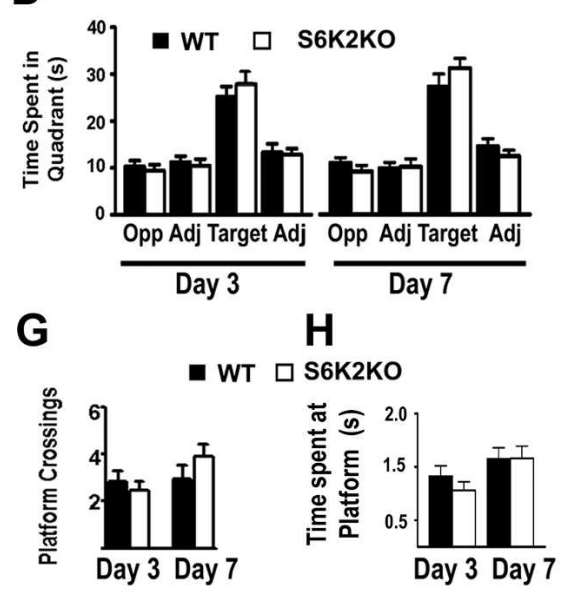

K

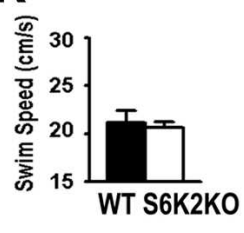

Figure 3. S6K1 knockout mice have a modest spatial learning deficit in the Morris water maze. $(A, B)$ Training latencies are normal in S6K1 knockout (KO) $(A)$ and S6K2 KO $(B)$ mice. $(C, D)$ Probe trials performed at the end of training on days three and seven indicate that the KO mice exhibit normal preference for the quadrant that contained the platform (Target) compared with the adjacent (Adj) and opposite (Opp) quadrants in S6K1 KO $(C)$ and S6K2 KO $(D)$ mice. Percent of time spent in target quadrant on Day 3: WT $=50 \pm 2, n=27 ;$ S6K1 KO $=47 \pm 3, n=24 ; W T=42 \pm 4, n=20$; S6K2 $\mathrm{KO}=46 \pm 3, \mathrm{n}=20$. Percent of time spent in target quadrant on Day 7: WT $=57 \pm 3$; S6K1 $\mathrm{KO}=60 \pm 3 ; \mathrm{WT}=43 \pm 4 ; \mathrm{S} 6 \mathrm{~K} 2 \mathrm{KO}=50 \pm 3$. (E) S6K1 KO mice exhibit a deficit in spatial memory for the exact location of the platform on day 3 (measured by the number of platform crossings) but normal memory by day 7. (F) S6K1 KO mice also spent less time at the location of the platform on day 3 but not on day 7. Platform crossings (number) and time spent at target location (sec), respectively, on day $3: \mathrm{WT}=3.2 \pm 0.4$ and $1.41 \pm 0.09 ; \mathrm{S} 6 \mathrm{~K} 1 \mathrm{KO}=2.3 \pm 0.3$ and $0.96 \pm 0.14$; on day 7 : $\mathrm{WT}=4.80 \pm .0 .04$ and $2.1 \pm 0.2 ; \mathrm{S} 6 \mathrm{~K} 1 \mathrm{KO}=4.7 \pm 0.4$ and $2.1 \pm 0.2$. (G) S6K2 KO mice show normal spatial memory measured in platform crossings on Days 3 and 7. (H) Similarly, S6K2 KO mice spent normal time at the location of the platform during probe trials on Days 3 and 7. (I, K) S6K1 KO mice exhibit a mild impairment in swim speed during a 60 -s test $(88.7 \pm 5.3 \%$ of WT) that is not apparent in S6K2 KO mice. $(J, L)$ To measure visual acuity and motivation in the water maze, a visible cue was placed onto a submerged platform in a novel area of the pool and the latency to find that platform was measured over four training trials. In the visible platform version of the Morris water maze, S6K1 KO (J) and S6K2 KO (L) were able to achieve similar training latencies, demonstrating that visual acuity and motivational behavior was normal. $\left({ }^{*}, P<0.05\right.$ compared with WT littermates).

The hippocampus is known to be important for the expression of contextual fear learning, a task that revealed selective deficits in the S6K mutant mice (see Fig. 1A,B). This led us to examine the expression of synaptic plasticity in the hippocampus, which is often studied as a possible cellular correlate of memory. First, we examined the basic neuroanatomy of the hippocampus and quantified basal synaptic transmission in the S6K1- and S6K2-deficient mice. No abnormalities were found in (1) gross morphology of the hippocampus (Fig. 4A), (2) synaptic transmission as measured in input/output curves in recordings at
$\mathbf{L}$

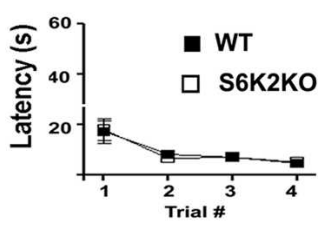

the Schaffer collateral-CA1 synapse (Fig. 4B,C), and (3) paired-pulse synaptic facilitation, a measure of short-term presynaptic plasticity (Fig. 4D,E). These findings suggest that S6K mutant mice are suitable models for studies of longterm synaptic plasticity.

We next examined two forms of enduring synaptic plasticity that have previously been reported to require protein synthesis: L-LTP elicited by 4 trains of high-frequency stimulation (HFS) or LLTP elicited by 3 trains of $\theta$ burst stimulation (TBS). In previous studies, either the general protein synthesis inhibitor anisomycin or the mTOR inhibitor rapamycin, which selectively decreases S6K activity, reduced L-LTP one to two hours following the final train of stimulation (Nguyen and Kandel 1997; Alarcon et al. 2004; Kelleher et al. 2004; Banko et al. 2005). In contrast, we observed no reduction in L-LTP in either the S6K1- or the S6K2-deficient mice up to three hours after the final train of HFS (Fig. 5). L-LTP elicited by two trains of HFS also is sensitive to rapamycin and anisomycin and has been accompanied with the selective phosphorylation of S6K1 (Cracco et al. 2005; Tsokas et al. 2005). Therefore, we measured this form of LTP specifically in S6K1-deficient mice and observed that it also was normally expressed (Fig. 6A). To further confirm that L-LTP was normal in S6K1-deficient mice, we monitored expression $4.5 \mathrm{~h}$ after induction (Fig. 6B). Our findings demonstrate that there is not a deficit in L-LTP in S6K-deficient mice as one might expect.

Because robust induction protocols did not alter the expression of L-LTP in S6K-deficient mice, we proceeded to determine whether early-phase LTP (ELTP) elicited with one train of HFS, which is typically protein synthesis independent, was altered in these mice. We observed that E-LTP in the S6K1deficient mice was more transient than E-LTP in wild-type mice (Fig. 7A). In contrast, E-LTP in the S6K2 mutant mice was indistinguishable from E-LTP in wild-type mice (Fig. 7B). Our results indicate that S6K1, but not S6K2, uniquely participates in protein synthesisindependent E-LTP in the hippocampus. Because of the surprising result that protein synthesisdependent L-LTP was not altered in the S6K1-deficient mice, we examined whether there were compensatory changes in either upstream regulators or downstream effectors of S6K1 in the S6K1deficient mice following induction of L-LTP. Similar to previous findings (Sanna et al. 2002; Kelleher et al. 2004; Tsokas et al. 2007), we found that Akt and S6 phosphorylation were significantly elevated in wild-type mice following the induction of LLTP (Fig. 8). In slices from S6K1-deficient mice, L-LTP induction modestly elevated S6 phosphorylation, but the elevation was not 
Table 1. Movement and anxiety behavior in S6K knockout mice

\begin{tabular}{lrrrr}
\hline & $\begin{array}{c}\text { WT } \\
(\mathbf{n}=\mathbf{1 2})\end{array}$ & $\begin{array}{c}\text { S6K1KO } \\
(\mathbf{n}=\mathbf{2 1})\end{array}$ & $\begin{array}{c}\text { WT } \\
(\mathbf{n}=\mathbf{1 1})\end{array}$ & \begin{tabular}{c}
\multicolumn{1}{c}{ S6K2KO } \\
$(\mathbf{n}=\mathbf{8})$
\end{tabular} \\
\hline $\begin{array}{l}\text { Open field behavior } \\
\quad \text { Horizontal activity }(\times 100)^{\mathrm{a}}\end{array}$ & $6.4 \pm 0.5$ & $3.8 \pm 0.5^{\mathrm{b}}$ & $4.7 \pm 0.5$ & $5.2 \pm 0.6$ \\
$\quad$ Vertical activity $(\times 10)^{\mathrm{a}}$ & $2.8 \pm 0.5$ & $1.1 \pm 0.4^{\mathrm{b}}$ & $1.3 \pm 0.2$ & $1.6 \pm 0.3$ \\
$\quad$ Total movements $(\times 10)$ & $3.3 \pm 0.3$ & $2.2 \pm 0.4^{\mathrm{c}}$ & $2.4 \pm 0.2$ & $2.4 \pm 0.3$ \\
$\quad$ Time spent moving (min) & $6.0 \pm 0.7$ & $3.0 \pm 0.7^{\mathrm{b}}$ & $3.6 \pm 0.6$ & $5.1 \pm 0.7$ \\
$\quad \begin{array}{l}\text { Distance moved }(\times 1000, \mathrm{~cm}) \\
\text { Percent time (center/periphery) }\end{array}$ & $3.4 \pm 0.4$ & $1.7 \pm 0.5^{\mathrm{b}}$ & $2.4 \pm 0.5$ & $3.5 \pm 0.6$ \\
& $12.4 \pm 3.0$ & $15.2 \pm 7.8$ & $7.2 \pm 1.8$ & $5.0 \pm 1.8$ \\
Rotating rod performance & & & & \\
$\quad$ First trial latency to fall $(\mathrm{s})$ & $65 \pm 14$ & $73 \pm 11$ & $64 \pm 10$ & $64 \pm 14$ \\
$\quad$ Eighth trial latency to fall (s) & $163 \pm 23$ & $159 \pm 14$ & $208 \pm 15$ & $190 \pm 20$ \\
\hline
\end{tabular}

S6K1 knockout mice have abnormal hypoactive exploratory behavior. Open Field Behavior: Mice were placed into the center of a brightly lit box and motor movement was automatically tracked over a period of 30 min. S6K1 knockout (KO) mice displayed deficits in all measures of movement. In contrast, S6K2 KO mice were comparable with wild-type mice in the same measures of movement. Because mice tend to avoid the center of the open field, the percentage of time moving in the center compared with the periphery is used as a measure of anxiety. S6K1 KO and S6K2 KO animals spent a comparable proportion of time in the center of the box as wild type, indicating that this behavior is normal in both the S6K1 and S6K2 KO mice. It should be noted that strain-specific differences were apparent among the wild-type mice from each strain. Rotating Rod Performance: Mice were placed onto a rotating rod that started at $4 \mathrm{rpm}$ and incrementally accelerated each $20 \mathrm{sec}$ to a final $40 \mathrm{rpm}$ and the latency to fall was recorded. Eight trials were performed over a span of two days (4 trials/day with an intertrial interval of $1 \mathrm{~h}$ ). S6K1 KO and S6K2 KO mice performed normally on the rotating rod task during both the initial trial and final trial. Learning curves were indistinguishable between $\mathrm{S} 6 \mathrm{~K} 1 \mathrm{KO}$, S6K2 KO, and respective wild-type littermates (data not shown). Consistent with previous reports, S6K1 KO mice have decreased body weight ( $86 \pm 5 \%$ of wild type, $\mathrm{P}<0.05)$, whereas S6K2 KO mice maintain normal body weight (102 $\pm 4 \%$ of wild type, $\mathrm{P}>0.05)$ (Shima et al. 1998; Pende et al. 2004). However, this impairment in size did not affect performance in the rotating rod task. ${ }^{a}$ Horizontal and vertical activity are system-defined variables in Versamat software. ${ }^{\mathrm{b}} P<0.001$ with a Student's $t$-test.

${ }^{c} P<0.05$ with a Student's $t$-test.

statistically significant (Fig. 8A,B). We also observed dramatic enhancement of basal Akt phosphorylation and L-LTP-induced Akt phosphorylation in slices from S6K1-deficient mice (Fig. 8A,C). S6K1-deficient mice expressed normal levels of basal S6 phosphorylation (Fig. 8A,B). It should be mentioned that other kinases can also phosphorylate the S6 phosphorylation site we examined and could be compensating for the lack of S6K1 by enhancing its phosphorylation of this site (Roux et al. 2007). In contrast to a recent study in rat hippocampal slices (Tsokas et al. 2007), we did not observe an increase in S6 levels following the induction of L-LTP. Our findings demonstrate that removal of S6K1 results in elevated basal levels of phosphorylated Akt that are further increased following induction of L-LTP.

\section{Discussion}

Our behavioral studies indicate that S6K1-deficient mice have specific deficits in memory acquisition based on multiple tasks. Contextual fear memory was compromised as early as one hour after training (Fig. 1C), aversive conditioned taste memory was poorly expressed and quickly degraded during extinction training (Fig. 2C,D), and precise spatial memory was not properly acquired after modest training (Fig. 3E,F). In parallel, we found that E-LTP also was impaired in S6K1-deficient mice (Fig. 7A). Surprisingly, protein synthesis-dependent L-LTP was intact in S6K1-deficient mice (Figs. 5A,C, 6A,B), indicating that S6K1 may not be required for the synthesis of de novo proteins necessary for enduring LTP. Together these findings suggest that S6K1 is critical for the early phases of memory and plasticity that are prerequisite for the enduring synaptic modifications in these processes.

Interestingly, we found elevated basal levels of phosphorylated Akt in hippocampal slices from S6K1-deficient mice, which were further elevated in response to L-LTP inducing stimuli (Fig.
$8 \mathrm{~A}, \mathrm{C})$. This finding is in line with the observation that S6K1-deficient mice are protected from aging- and diet-associated obesity due to the loss of a negative feedback loop extended from S6K1 to the insulin receptor substrate 1 (IRS1) (Um et al. 2004). Emerging reports support direct regulation of Akt activity by S6K1 through similar negative feedback mechanisms that involve phosphorylation of the IRS1 (Radimerski et al. 2002a,b; Um et al. 2004). Elevated Akt in the S6K1-deficient hippocampus might indicate that the insulin receptor family of tyrosine kinases normally participates in the expression of hippocampal LTP. This observation is further supported by the finding that inhibitors of the insulin receptor family signaling pathway produce dramatic reductions in PI3K-Akt activity that is associated with impaired L-LTP (Townsend et al. 2007). In parallel, it is known that Akt activity is required for the expression of LTP (Sanna et al. 2002). Taken together, these observations suggest that L-LTP is preserved in S6K1-deficient mice because they possess elevated Akt activity.

We were surprised to observe a deficit in E-LTP and not L-LTP in our studies of S6K1-deficient mice (Figs. 5A, 6A, 7A). This suggests that E-LTP requires phosphorylation of an S6K1 substrate not directly involved in translation control because E-LTP is usually protein synthesis independent. A candidate S6K1 substrate in this regard is neurabin, a synaptic cytoskeleton protein that has been shown to bind S6K1 (Burnett et al. 1998). Whether S6K1neurabin interactions are required for E-LTP remains to be determined.

E-LTP typically is associated with the activation of multiple protein kinases (Soderling and Derkach 2000) and during induction of L-LTP, similar complements of kinases might be activated to recruit more signaling pathways that directly regulate protein synthetic machinery (Abel et al. 1997; Atkins et al. 2005). Our findings suggest that in the absence of S6K1, the PI3K-AktmTOR signal transduction pathway is able to promote normal protein synthetic capacity through alternative substrate regulation. Aside from S6K1, a major target of the PI3K-mTOR pathway that impacts the expression of protein synthesis is eIF4E-binding protein (4E-BP). Phosphorylation of 4E-BP by the PI3K-AktmTOR signaling pathway releases sequestered eIF4E promoting the formation of the cap-binding complex and subsequent translation. Moreover, genetic deletion of $4 \mathrm{E}-\mathrm{BP} 2$, the predominant isoform of $4 \mathrm{E}-\mathrm{BP}$ in the mouse hippocampus, results in impaired L-LTP (Banko et al. 2005). Our data support the notion that the protein-synthetic capacity associated with L-LTP is preserved in S6K1-deficient mice via phosphorylation of 4E-BP via the PI3KAkt-mTOR pathway.

We found that the S6K1-deficient mice have a number of learning and memory impairments. It is possible that the context-specific fear memory impairment present in the S6K1deficient mice results from a lack of normal exploratory behavior. The deficit in exploratory movements in the open field test (Table 1) might be explained by abnormal muscle tissue reported previously in the S6K1 mutant mice (Ohanna et al. 2005). However, the S6K1 knockout mice were able to achieve peak perfor- 
A
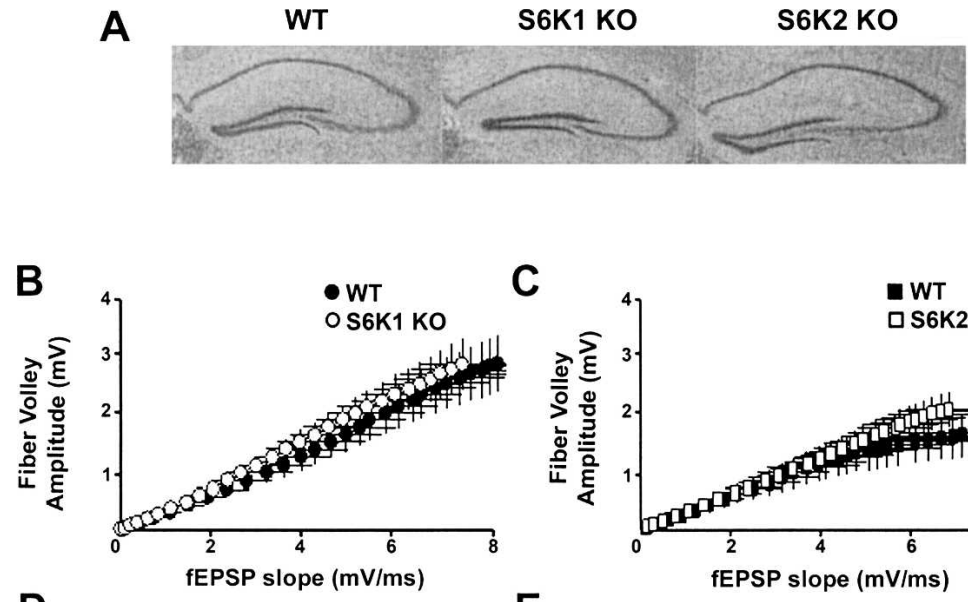

D

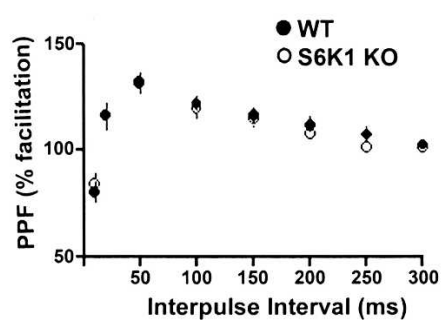

C

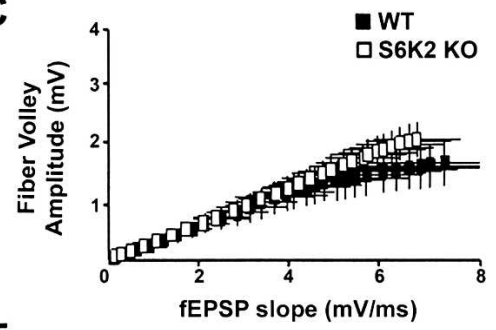

E

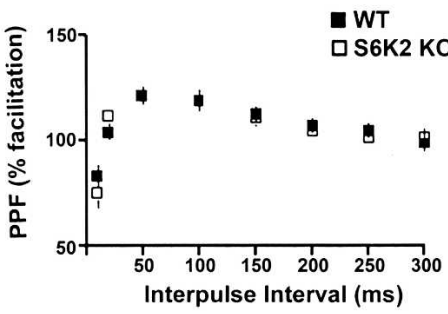

Figure 4. Gross morphology of the hippocampus and basal measures of synaptic transmission in the Schaffer collateral pathway are normal in S6K knockout mice. ( $A$ ) Nissl stains of the hippocampus revealed that WT (left), S6K1 knockout (KO) (middle), and S6K2 KO (right) have comparable hippocampal architecture. $(B, C)$ For every slice, a stimulus was delivered at ascending intensity $(0-15 \mathrm{~V})$ and the amplitude of the fiber volley (the input) was measured as an indicator of the size of the ascending fiber stimulus. The initial slope $(0.2-0.3 \mathrm{msec}$ after the cessation of the fiber volley) of the population field excitatory postsynaptic potential (fEPSP) also was assessed as an indicator of the output. (B) Comparison of the fiber volley amplitude (input) to the evoked fEPSP slope (output) revealed a regression curve similar to one in S6K1 KO $\left(R^{2}=0.997, n=15\right.$ slices $)$ and WT slices $\left(R^{2}=0.999, n=15\right.$ slices). (C) A similar finding was found in S6K2 KO $\left(R^{2}=0.999, n=14\right.$ slices $)$ and WT slices $\left(R^{2}=0.974\right.$, $\mathrm{n}=14$ slices $)$. $(D, E)$ Paired stimuli at ascending interstimulus intervals ranging from 10 to $300 \mathrm{msec}$ were delivered to examine presynaptic facilitation. The amplitude of the second response of each pair was divided by the first and plotted as a function of the time between the first and second pulse. Paired-pulse facilitation was indistinguishable in hippocampal slices from S6K1 KO (D) and S6K2 KO (E) mice.

mance on the rotating rod motor task and acquire similar latencies during hidden and visible platform water maze training (Fig. $3 \mathrm{~A}, \mathrm{~J}$; Table 1). Therefore, it is difficult to ascertain whether the hypoactive exploratory behavior results from muscular impairment, a lack of inquisitiveness to novelty, or a combination of these factors. It is well established that exploratory behavior within novel environments produces intricate patterns of place cell activity within the hippocampus that are associated with somatosensory, olfactory, and visual experience that are important for acquisition (O'Keefe and Dostrovsky 1971; O'Keefe 1993; Eichenbaum et al. 1994; Kentros et al. 2004). This suggests that S6K1 may normally promote salient experience-dependent acquisition of contextual information.

In contrast with S6K1-deficient mice, S6K2-deficient mice exhibited behavioral deficits that rely on long-term memory encoding. S6K2 null mice were found to have a modest alteration in contextual fear memory present seven days after training (Fig. 1D). In the latent inhibition of CTA, which requires the retention of novelty taste learning over a longer period of time, S6K2 knockout mice performed poorly (Fig. 2E). These findings suggest that S6K2 is important for the encoding of long-term memories unique to one-trial learning tasks. S6K2 is known to be highly restricted to the nucleus of cells (Lee-Fruman et al. 1999; Park et al. 2002). This observation suggests that S6K2 influences tran- scription, which, similar to translation, is involved in the expression of memory formation and the expression of L-LTP.

Interestingly, the S6K2-deficient mice exhibited no L-LTP phenotype utilizing multiple induction protocols (Figs. 5B,D, 7B). These findings support the hypothesis that $\mathrm{S} 6 \mathrm{~K} 2$ is not required for LTP in the hippocampus. Due to the manifestation of memory phenotypes in S6K2 knockout mice, further inquiry into the potential contribution of S6K2 in other forms of synaptic plasticity appears to be warranted. Our finding that latent inhibition of CTA is selectively impaired in the S6K2-deficient mice suggests that areas of the brain distinct from the hippocampus may be involved.

There are additional issues that should be considered with respect to our behavioral analysis of S6K1- and S6K2deficient mice. To preserve viability, we maintained each strain on their respective congenic backgrounds. The possibility remains that these strains themselves are slightly different and may account for the observation of disparate differences between the S6K-deficient mice. However, we observed comparable behavioral responses in the wild-type mice and utilized only littermates for the behavioral characterization of the S6Kdeficient mice. Another consideration is that because S6K1 and S6K2 are homologous, compensatory elevation of each gene in our single knockouts might occur. We have found that the expression of $\mathrm{S} 6 \mathrm{~K} 1$ protein is not altered in whole hippocampal homogenates of S6K2deficient mice (M.D. Antion and E. Klann, unpubl.). In many body tissues of the S6K1-deficient mice, S6K2 mRNA is elevated many fold (Shima et al. 1998). However, the levels of S6K2 mRNA are increased only 1.3-fold in the brains of S6K1deficient mice (Shima et al. 1998). These findings, together with our observations of unique learning and physiological phenotypes in each S6K mutant mouse, indicate that it is unlikely that compensatory function occurs in the brain of each S6K-deficient mouse.

All together, our findings demonstrate disparate deficits in learning, memory, and hippocampal synaptic plasticity in S6K1and S6K2-mutant mice. Specific functions of each of these S6 kinases can be inferred from our studies, and these functions are likely to be derived from the unique localization and regulation of each S6 kinase within the brain. S6K1 is known to be localized in both the nucleus and cytosol of cells, whereas S6K2 is largely restricted to the nucleus (Lee-Fruman et al. 1999; Park et al. 2002). Importantly, specific binding partners for S6K1 that are not shared by S6K2 have recently been identified (Richardson et al. 2004; Holz et al. 2005; Ruvinsky and Meyuhas 2006). Of interest, the ribosomal protein S6 phosphorylation site-deficient mouse displays phenotypes that include a decrease in body mass and cellular proliferation reminiscent of the S6K1-deficient mouse (Ruvinsky et al. 2005). This suggests that S6 is a critical substrate of S6K1 rather than S6K2 because the S6K2-deficient mouse does not share this characteristic. In comparison with the 
A

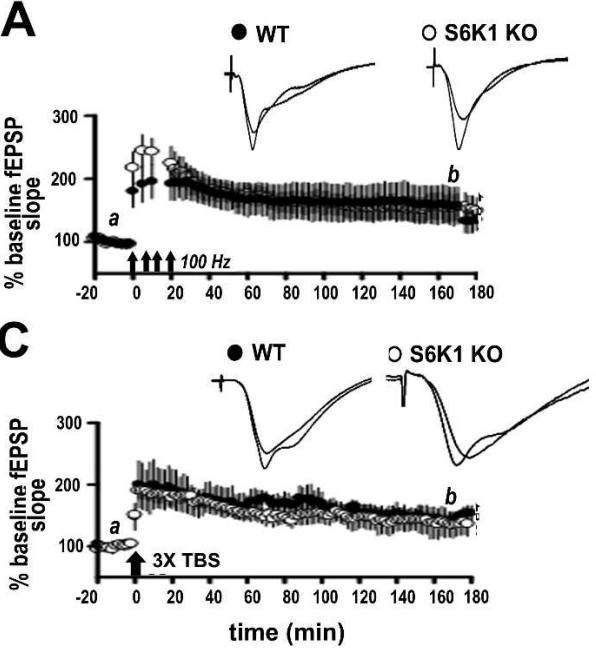

B

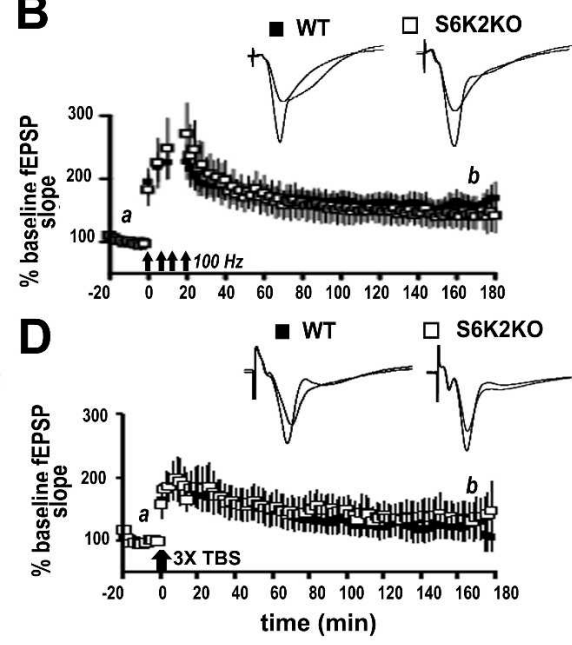

Figure 5. L-LTP is normally expressed in S6K knockout mice. $(A, B)$ L-LTP evoked with four spaced trains of HFS is normally expressed in S6K1 knockout (KO) mice (open circles, $\mathrm{n}=7$ slices, 7 mice) compared with wild-type (WT) littermates (solid circles, 7 slices, 7 mice) (A) and in S6K2 KO mice (open squares, $\mathrm{n}=8$ slices, 8 mice) compared with WT littermates (solid squares, $\mathrm{n}=6$ slices, 6 mice) (B). $(C, D)$ L-LTP evoked with 3 trains of $\theta$-burst stimulation (TBS) also is normally expressed in S6K1 KO mice (open circles, $\mathrm{n}=7$ slices, 7 mice) compared with WT mice (solid circles, 5 slices, 5 mice) (C) and in S6K2 KO mice (open squares, $\mathrm{n}=10$ slices, 9 mice) compared with WT mice (solid squares, $\mathrm{n}=10$ slices, 8 mice) $(D)$. The representative traces shown above each graph were taken $10 \mathrm{~min}$ before $(a)$ and 170 min after $(b)$ the induction of L-LTP.

rich history of research conducted on S6K1, less is known about S6K2, which was more recently discovered. In contrast with S6K1-deficient mice, S6K2 null mice do not have any noticeable physical phenotypes. However, removal of S6K2 in addition to S6K1 results in perinatal lethality in mice, which demonstrates that S6K2 may have a vital physical function (Pende et al. 2004). It is important to note that $\mathrm{S6K2}$ contains several unique structural features that may confer functional specificity distinct from S6K1. For example, an SH3-like binding domain not found in S6K1 is present in S6K2 (Gout et al. 1998). Further studies that examine the selective activation of each S6 kinase will be required to appreciate the contribution of the individual S6 kinases toward cognitive processing.

\section{Materials and Methods}

\section{S6K1- and S6K2-deficient mice}

S6K1 and S6K2 congenic knockout mice were created by replacing each respective gene with a neomycin cassette that resulted in a direct deletion of each gene as previously described (Pende et al. 2004). The S6K1 mutant mice were initially generated on a mixed 129/SveJ $\times \mathrm{C} 57 \mathrm{Bl} / 6$ line (Shima et al. 1998), and the S6K2 mutant mice were initially generated on a mixed 129/ OlaHsd $\times$ C57Bl/6 line (Pende et al. 2004). Each mouse strain was outcrossed at least twice to $\mathrm{C} 57 \mathrm{~B} 16 / \mathrm{J}$ mice upon receiving and was maintained on the respective congenic line where inbreeding was minimized. This was done to preserve hybrid vigor, as we observed a decrease in viable knockout mice after the fourth backcross to C57Bl6/J mice. For all studies, heterozygous mice from each strain were crossed to produce wild-type, heterozygous knockout, and homozygous knockout mice. Mice were genotyped by PCR of tail digests as described previously (Shima et al. 1998; Pende et al. 2004). All mice were treated in accordance to the guidelines of the Baylor College of Medicine Institutional Animal Care and Use Committee. For behavior assays, all littermates were evaluated at three to five months of age. In most cases, heterozygous mice performed similarly to wild-type mice unless otherwise described in the text.
Associative learning and memory

For associative fear learning, mice were given $3 \mathrm{~min}$ to explore a conditioning chamber prior to receiving two spaced pairings of a 2-msec, $0.9-\mathrm{mA}$ foot shock preceded by a $30-\mathrm{sec}, 90-\mathrm{dB}$ white noise. Fear memory was measured via a motion-sensitive camera that recorded the percentage of time the mice spent not moving (freezing). For contextual memory, mice were placed back into the conditioning chamber for $5 \mathrm{~min}$. For cued fear memory, $1 \mathrm{hr}$ after the context test the mice were placed into a novel environment for $3 \mathrm{~min}$ followed by a 3-min exposure to the auditory cue. For conditioned taste aversion (CTA), mice maintained on a water deprivation schedule were presented with saccharin $(0.5 \%)$ as a novel taste and received an intraperitoneal injection of $\mathrm{LiCl}(0.14 \mathrm{M}$, $2 \%$ of body weight) $1 \mathrm{hr}$ later to produce a sense of malaise. Two days later, mice were presented a choice of water or saccharin, and the consumption of liquids measured. The aversion index is defined as water/(water + saccharin) (in $\mathrm{mL}$ ) consumed in the test. In the latent inhibition paradigm (LI), mice were treated as in CTA except that they were preexposed twice to saccharin prior to pairing saccharin with $\mathrm{LiCl}$ injection. The aversion test was repeated three consecutive days after training to measure the coefficient of extinction. For natural taste aversion, mice received a choice between water and 0.04\% quinine (an aversive taste).
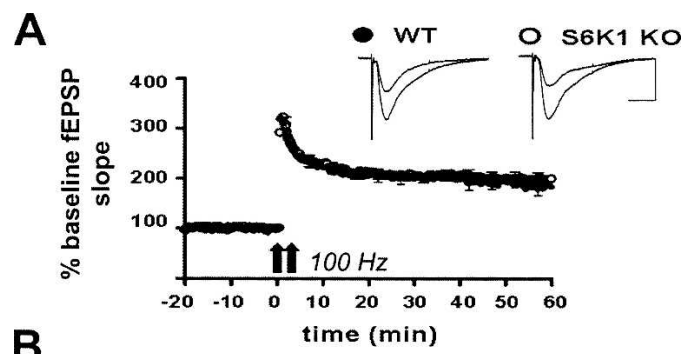

B

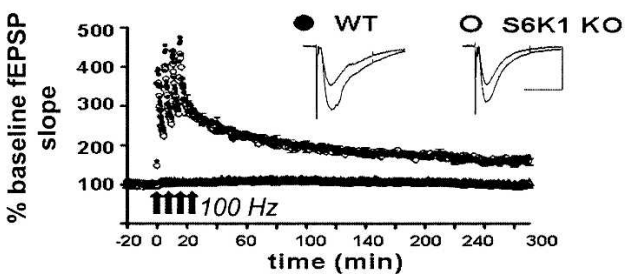

Figure 6. L-LTP is normally expressed in S6K1 knockout mice. (A) L-LTP was elicited with 2 trains of $100 \mathrm{~Hz}$ (intertrain interval of $30 \mathrm{sec}$ ) and monitored $60 \mathrm{~min}$ after induction. No differences were observed in S6K1 knockout (KO) (open circles, $\mathrm{n}=8$ slices) and wild-type (WT) (solid circles, $\mathrm{n}=13$ slices). Scale bar, $200 \mathrm{msec}, 0.5 \mathrm{mV}$. (B) Similarly, L-LTP evoked with 4 spaced trains of $100 \mathrm{~Hz}$ stimulation (intertrain interval of 5 $\mathrm{min}$ ) revealed no observable differences up to $300 \mathrm{~min}$ after induction in S6K1 KO (open circles, $\mathrm{n}=10$ slices) and WT (solid circles, $\mathrm{n}=10$ slices). At the bottom of the panel, basal responses in S6K1 KO slices (open triangles, $\mathrm{n}=10$ slices) were comparable with WT (solid triangles, $\mathrm{n}=10$ slices) in unstimulated slices over a similar time course. Representative traces before and after LTP induction are exhibited to the right of each graph. Scale bar, $400 \mathrm{msec}, 0.5 \mathrm{mV}$. 
A

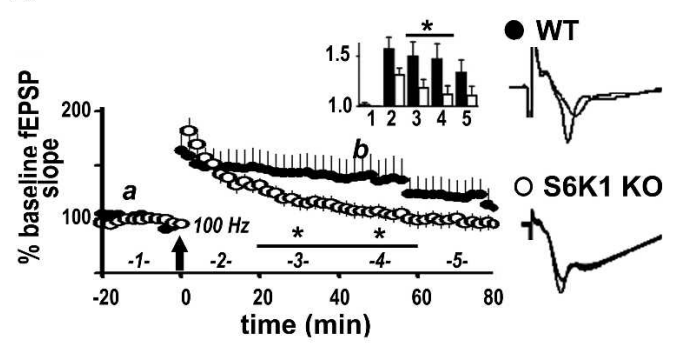

B

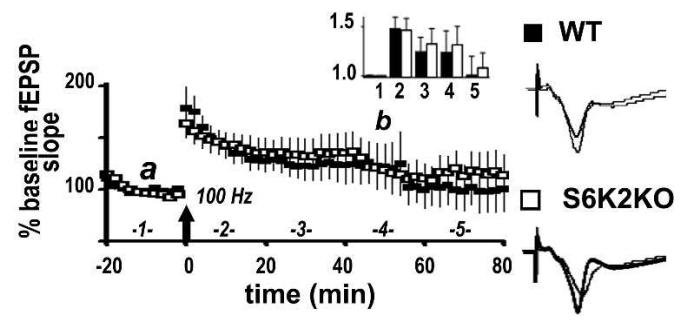

Figure 7. S6K1 knockout mice have a deficit in E-LTP. (A) One train of HFS was delivered to slices from either S6K1 KO mice or WT littermates and fEPSPs monitored 100 min after. (Inset) Data binned into columns of 20-min increments and labeled as indicated on the large graph on the $\mathrm{x}$-axis and fold-increase in potentiation on the $y$-axis. At 20-60 min after LTP induction, S6K1 KO mice (open circles and bars, $\mathrm{n}=11$ slices from 8 mice) exhibit decreased potentiation compared with WT mice (solid circles and bars, $\mathrm{n}=9$ slices, 8 mice). Values for time points, expressed as $\%$ baseline fEPSP, are as follows: $20-40$ min after HFS: WT $=150 \pm 14$, S6K1 KO $=118 \pm 2,{ }^{*} P<0.05 ; 40-60$ min after HFS: WT $=147 \pm 15$, S6K1 KO $=112 \pm 3, * P<0.05$. At $60-80 \mathrm{~min}$ after HFS, potentiation in the $\mathrm{S} 6 \mathrm{~K} 1 \mathrm{KO}$ slices returned to baseline $(\mathrm{S} 6 \mathrm{~K} 1 \mathrm{KO}=110 \pm 10, P>0.05$ compared with baseline), whereas potentiation in the WT slices returned to baseline $80-100 \mathrm{~min}$ after induction (data not displayed on graph: $W T=120 \pm 11, P>0.05$ compared with baseline). (B) The same induction protocol revealed normal E-LTP in slices from S6K2 KO mice (open squares and bars, $\mathrm{n}=9$ slices, 8 mice) in comparison with WT mice (solid squares and bars, $\mathrm{n}=8$ slices, 8 mice). ( $A, B)$ Representative traces 10 min before $(a)$, and 45 min after $(b)$, induction are shown on the right. Statistics were calculated with a paired two-tailed Student's $t$-test.

\section{Morris water maze}

Mice were trained to find a submerged platform $(10 \times 10 \mathrm{~cm}$ square) in a pool of water ( $1.38 \mathrm{~m}$ diameter) surrounded by visually noticeable cues over seven days that consisted of four trials per day. At the end of the third and seventh training days, the platform was removed and the swim paths of the mice were measured with Noldus Ethovision software over a period of 1 $\min$.

\section{Open field assessment}

Mice were placed into the center of a brightly illuminated chamber $(43 \times 42 \times 30 \mathrm{~cm})$ and allowed to explore for a period of 30 min. Activity was tracked by an automated computer system program (Versamax, Accusan Inc., Columbus, $\mathrm{OH}$ ).

\section{Electrophysiology}

Hippocampal slices were prepared with methods previously described (Hou and Klann 2004). Slices were incubated at $30^{\circ} \mathrm{C}$ within a humidified interface chamber perfused with oxygenated ACSF (containing in mM: $125 \mathrm{NaCl}, 2.5 \mathrm{KCl}, 1.25 \mathrm{NaH}_{2} \mathrm{PO}_{4}, 25$ $\mathrm{NaHCO}_{3}, 25$ glucose, $1 \mathrm{MgCl}_{2}, 2 \mathrm{CaCl}_{2}$ gassed with $95 \% \mathrm{O}_{2} / 5 \%$ $\mathrm{CO}_{2}$ ) at least two hours prior to recording. For all recordings, a bipolar platinum stimulating electrode was placed onto the Schaffer collaterals and field potentials were measured with a glass micropipette (1-5 M $\Omega$ ) in the stratum radiatum. Slices re- ceived stimuli within the range of $0-15 \mathrm{~V}$ intensity, a frequency of $0.33 \mathrm{~Hz}$, and total duration of $0.05 \mathrm{msec}$. All signals collected were analyzed via Patchclamp Version 8.2. Test pulses that yielded a 40\%-50\% maximal fEPSP were delivered every $20 \mathrm{sec}$ and averaged over $2 \mathrm{~min}$. Basal responses were measured $20 \mathrm{~min}$ prior to the stimuli described. For the induction of E-LTP, a 1-sec train of $100 \mathrm{~Hz}$ HFS was delivered at 50\% maximal intensity. For L-LTP, four trains of HFS were delivered with an intertrain inter-
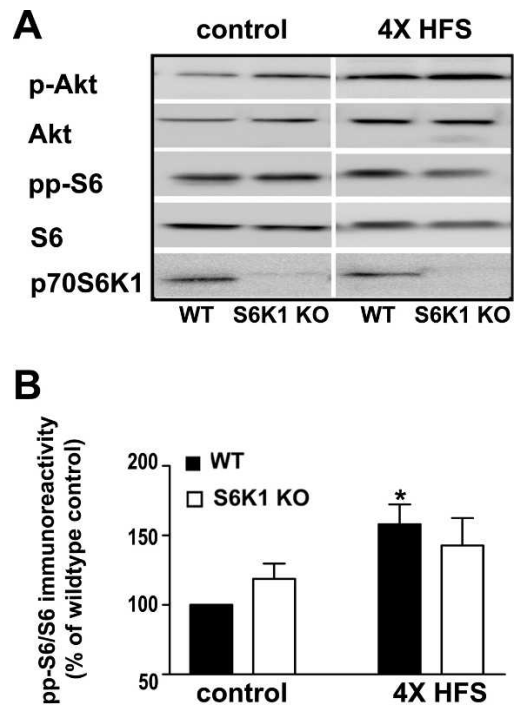

C

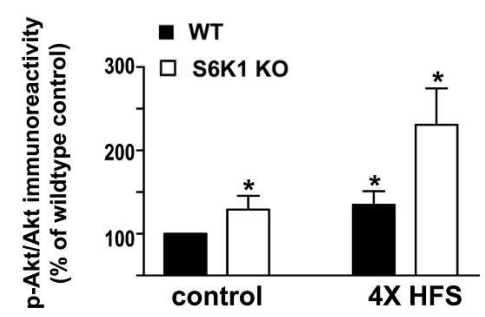

Figure 8. S6K1-deficient mice have increased basal levels of phosphorylated Akt that are further enhanced following L-LTP-inducing stimulation. Hippocampal slices from either wild-type (WT) or S6K1 knockout (S6K1 KO) mice were placed in the recording chamber and given either test pulses or L-LTP inducing stimulation (four trains of $100 \mathrm{~Hz}$ stimulation with a 5-min intertrain interval). Slices were removed $10 \mathrm{~min}$ after delivery of the stimulation ( $4 \times \mathrm{HFS}$ ) or after an equivalent time of receiving test pulses (control), frozen, and microdissected; and CA1 was immediately homogenized and analyzed on Western blots with the indicated antibodies. (A) Representative Western blots for Ser 473 phosphorylated Akt (p-Akt), total Akt (Akt), Ser235/Ser236 phosphorylated ribosomal protein $\mathrm{S6}(\mathrm{pp}-\mathrm{S6})$, total ribosomal protein $\mathrm{S6}(\mathrm{S6})$, and the $70-\mathrm{kD}$ isoform of S6K1 (p70S6K1). (B) Phosphorylated levels of S6 were significantly increased in WT slices following $4 \times \mathrm{HFS}$ (solid bars, control $=100 \pm 12 \%$ of control, $4 \times \mathrm{HFS}=158 \pm 14 \%$ of control, $\left.\mathrm{n}=3,{ }^{*} P<0.05\right)$. In contrast, a modest increase in phosphorylated levels of $\mathrm{S} 6$ that was not statistically significant was observed in S6K1 KO slices following $4 \times$ HFS (open bars, control $=119 \pm 11 \%$, $4 \times \mathrm{HFS}=142 \pm 20 \%$ of control, $\mathrm{n}=3, \mathrm{P}=0.11)$. Immunoreactivity of pp-S6 was normalized to total S6. Values are means \pm SEM and plotted as \% wild-type control. (C) Phosphorylated levels of Akt were significantly increased in WT slices following $4 \times$ HFS (solid bars, control $=100 \pm 4 \%$ of control, $4 \times \mathrm{HFS}=134 \pm 16 \%$ of control, $\mathrm{n}=4,{ }^{*} P<0.05$ ). Levels of phosphorylated Akt were abnormally elevated in S6K1 KO mice in comparison with WT mice with and without L-LTP-inducing stimulation (open bars, control $=135 \pm 16 \%$ of control, $4 \times \mathrm{HFS}=232 \pm 48 \%$ of control, $\left.n=4,{ }^{*} P<0.05\right)$. Immunoreactivity of $p$-Akt was normalized to total Akt. Values are means \pm SEM and plotted as \% wild-type control. Statistics were calculated with one-way ANOVA with multiple comparisons on the raw data followed by a Tukey test where appropriate. 
val of $5 \mathrm{~min}$. L-LTP also was induced with two alternative protocols: three trains of TBS (10 bursts of $100 \mathrm{~Hz}$ stimulation, duration of $50 \mathrm{msec}$, delivered at a $5 \mathrm{~Hz}$ frequency), with an intertrain interval of $20 \mathrm{sec}$ or two trains of HFS with an intertrain interval of $30 \mathrm{sec}$.

\section{Western blotting}

Ten min after delivery of four trains of HFS, slices were immediately frozen on dry ice, and area CA1 was microdissected and homogenized in ice-cold buffer containing the following: $10 \mathrm{mM}$ HEPES, $150 \mathrm{mM} \mathrm{NaCl}, 1 \mathrm{mM}$ EDTA, $1 \mathrm{mM}$ EGTA, $10 \mathrm{mM}$ $\mathrm{Na}_{4} \mathrm{P}_{2} \mathrm{O}_{7}$, and $10 \mu \mathrm{l} / \mathrm{mL}$ of each of the following inhibitors: protease inhibitor cocktail 1, phosphatase inhibitor cocktail 1, and phosphatase inhibitor cocktail 2 (Sigma, St. Louis, MO). For each sample, 5-6 microsections were pooled together. Protein content was determined, and samples were resolved via SDS-PAGE and blotted onto polyvinylidene fluoride (PVDF) membranes in a methanol-based TRIS-glycine-SDS buffer. Each primary antibody was suspended into $0.2 \%$ I-Block in TTBS $(0.1 \%$ Tween 20$)$ in a total volume of 5-10 $\mathrm{mL}$ and incubated over the membrane with vigorous mixing either $2 \mathrm{~h}$ at room temperature or overnight at $4^{\circ} \mathrm{C}$. All primary antibodies were obtained from Cell Signaling Technology (Beverly, MA): Ser235/236 S6 monoclonal rabbit D57.2.2E (1:2500); S6 monoclonal rabbit 5G10 (1:2000); Ser 473 Akt monoclonal mouse 587F11 (1:1000); pan Akt (1:1000); and p70S6K (1:1000). Membranes were rinsed at least 3 times in TTBS, 5 min each, and incubated in secondary antibody conjugated to horseradish peroxidase $(1: 5000)$ in I-Block for $1-2 \mathrm{~h}$ more at room temperature. After a final set of TTBS rinses, membranes were suspended in ECL fluid for 1-5 min and exposed to Kodak XOMAT film for $30 \mathrm{~s}$ to $10 \mathrm{~min}$. Blots were analyzed using Scion Image densitometry (Scion, Frederick, MD). A one-way ANOVA was conducted where multiple comparisons within experiments were measured, followed by a Tukey test where appropriate. $P<0.05$ was considered statistically significant.

\section{Acknowledgments}

The S6K mice were obtained with permission from NOVARTIS (Basel, Switzerland). Dr. Richard Paylor and Dr. Corinne Spencer assisted with the Behavior Core at BCM supported by a MRDRRC grant. This work was supported by NIH grants NS34007, NS047384, and the FRAXA Research Foundation to E.K.

\section{References}

Abel, T., Nguyen, P.V., Barad, M., Deuel, T.A., Kandel, E.R., and Bourtchouladze, R. 1997. Genetic demonstration of a role for PKA in the late phase of LTP and in hippocampus-based long-term memory. Cell 88: 615-626.

Alarcon, J.M., Hodgman, R., Theis, M., Huang, Y.S., Kandel, E.R., and Richter, J.D. 2004. Selective modulation of some forms of Schaffer collateral-CA1 synaptic plasticity in mice with a disruption of the CPEB-1 gene. Learn. Mem. 11: 318-327.

Atkins, C.M., Selcher, J.C., Petraitis, J.J., Trzaskos, J.M., and Sweatt, J.D. 1998. The MAPK cascade is required for mammalian associative learning. Nat. Neurosci. 1: 602-609.

Atkins, C.M., Davare, M.A., Oh, M.C., Derkach, V., and Soderling, T.R. 2005. Bidirectional regulation of cytoplasmic polyadenylation element-binding protein phosphorylation by $\mathrm{Ca}^{2+} /$ calmodulin-dependent protein kinase II and protein phosphatase 1 during hippocampal long-term potentiation. $J$. Neurosci. 25: 5604-5610.

Banko, J.L., Poulin, F., Hou, L., DeMaria, C.T., Sonenberg, N., and Klann, E. 2005. The translation repressor 4E-BP2 is critical for eIF4F complex formation, synaptic plasticity, and memory in the hippocampus. J. Neurosci. 25: 9581-9590.

Bekinschtein, P., Katche, C., Slipczuk, L.N., Igaz, L.M., Cammarota, M., Izquierdo, I., and Medina, J.H. 2006. mTOR signaling in the hippocampus is necessary for memory formation. Neurobiol. Learn. Mem. 87: 303-307.

Belelovsky, K., Elkobi, A., Kaphzan, H., Nairn, A.C., and Rosenblum, K. 2005. A molecular switch for translational control in taste memory consolidation. Eur. J. Neurosci. 22: 2560-2568.

Burnett, P.E., Blackshaw, S., Lai, M.M., Qureshi, I.A., Burnett, A.F., Sabatini, D.M., and Snyder, S.H. 1998. Neurabin is a synaptic protein linking p70S6 kinase and the neuronal cytoskelton. Proc.
Natl. Acad. Sci. 95: 8351-8356.

Cammalleri, M., Lutjens, R., Berton, F., King, A.R., Simpson, C., Francesconi, W., and Sanna, P.P. 2003. Time-restricted role for dendritic activation of the mTOR-p70S6K pathway in the induction of late-phase long-term potentiation in the CA1. Proc. Natl. Acad. Sci. 100: $14368-14373$.

Chen, X., Garelick, M.G., Wang, H., Lil, V., Athos, J., and Storm, D.R. 2005. PI3 kinase signaling is required for retrieval and extinction of contextual memory. Nat. Neurosci. 8: 925-931.

Cracco, J.B., Serrano, P., Moskowitz, S.I., Bergold, P.J., and Sacktor, T.C. 2005. Protein synthesis-dependent LTP in isolated dendrites of CA1 pyramidal cells. Hippocampus 15: 551-556.

Dash, P.K., Orsi, S.A., and Moore, A.N. 2006. Spatial memory formation and memory-enhancing effect of glucose involves activation of the tuberous sclerosis complex-mammalian target of rapamycin pathway. J. Neurosci. 26: 8048-8056.

Davis, H.P. and Squire, L.R. 1984. Protein synthesis and memory: A review. Psychol. Bull. 96: 518-559.

Dorrello, N.V., Peschiaroli, A., Guardavaccaro, D., Colburn, N.H., Sherman, N.E., and Pagano, M. 2006. S6K1- and $\beta$ TRCP-mediated degradation of PDCD4 promotes protein translation and cell growth. Science 314: 467-471.

Dufner, A. and Thomas, G. 1999. Ribosomal S6 kinase signaling and the control of translation. Exp. Cell Res. 253: 100-109.

Eichenbaum, H., Otto, T., and Chen, N.J. 1994. Two functional compenents of the hippocampal memory system. Behav. Brain Sci. 17: 449-518.

Ferrari, S. and Thomas, G. 1994. S6 phosphorylation and the p70s6k/p85s6k. Crit. Rev. Biochem. Mol. Biol. 29: 385-413.

Francesconi, W., Cammalleri, M., and Sanna, P.P. 2004. The metabotropic glutamate receptor 5 is necessary for late-phase long-term potentiation in the hippocampal CA1 region. Brain Res. 1022: $12-18$.

Frey, U., Krug, M., Reymann, K.G., and Matthies, H. 1988. Anisomycin, an inhibitor of protein synthesis, blocks late phases of LTP phenomena in the hippocampal CA1 region in vitro. Brain Res. 452: $57-65$

Gonzalez-Mejia, M.E., Morales, M., Hernandez-Kelly, L.C., Zepeda, R.C., Bernabe, A., and Ortega, A. 2006. Glutamate-dependent translational regulation in cultured Bergmann glia cells: Involvement of p70S6K. Neuroscience 141: 1389-1398.

Gout, I., Minami, T., Hara, K., Tsujishita, Y., Filonenko, V., Waterfield, M.D., and Yonezawa, K. 1998. Molecular cloning and characterization of a novel p70 S6 kinase, p70 S6 kinase $\beta$ containing a proline-rich region. J. Biol. Chem. 273: 3061-3064.

Holz, M.K., Ballif, B.A., Gygi, S.P., and Blenis, J. 2005. mTOR and S6K1 mediate assembly of the translation preinitiation complex through dynamic protein interchange and ordered phosphorylation events. Cell 123: 569-580.

Horwood, J.M., Dufour, F., Laroche, S., and Davis, S. 2006. Signaling mechanisms mediated by the phosphoinositide 3-kinase/Akt cascade in synaptic plasticity and memory in the rat. Eur. J. Neurosci. 23: $3375-3384$.

Hou, L. and Klann, E. 2004. Activation of the phosphoinositide 3-kinase-Akt-mammalian target of rapamycin signaling pathway is required for metabotropic glutamate receptor-dependent long-term depression. J. Neurosci. 24: 6352-6361.

Jefferies, H.B., Reinhard, C., Kozma, S.C., and Thomas, G. 1994. Rapamycin selectively represses translation of the "polypyrimidine tract" mRNA family. Proc. Natl. Acad. Sci. 91: 4441-4445.

Kang, H. and Schuman, E.M. 1996. A requirement for local protein synthesis in neurotrophin-induced hippocampal synaptic plasticity. Science 273: 1402-1406.

Kelleher 3rd, R.J., Govindarajan, A., Jung, H.Y., Kang, H., and Tonegawa, S. 2004. Translational control by MAPK signaling in long-term synaptic plasticity and memory. Cell 116: 467-479.

Kentros, C.G., Agnihotri, N.T., Streater, S., Hawkins, R.D., and Kandel, E.R. 2004. Increased attention to spatial context increases both place field stability and spatial memory. Neuron 42: 283-295.

Klann, E. and Dever, T.E. 2004. Biochemical mechanisms for translational regulation in synaptic plasticity. Nat. Rev. Neurosci. 5: 931-942.

Lee-Fruman, K.K., Kuo, C.J., Lippincott, J., Terada, N., and Blenis, J. 1999. Characterization of S6K2, a novel kinase homologous to S6K1. Oncogene 18: 5108-5114.

Lenz, G. and Avruch, J. 2005. Glutamatergic regulation of the p70S6 kinase in primary mouse neurons. J. Biol. Chem. 280: 38121-38124

Manahan-Vaughan, D., Kulla, A., and Frey, J.U. 2000. Requirement of translation but not transcription for the maintenance of long-term depression in the CA1 region of freely moving rats. J. Neurosci. 20: $8572-8576$.

Meyuhas, O. 2000. Synthesis of the translational apparatus is regulated 
at the translational level. Eur. J. Biochem. 267: 6321-6330.

Nguyen, P.V. and Kandel, E.R. 1997. Brief $\theta$-burst stimulation induces a transcription-dependent late phase of LTP requiring cAMP in area CA1 of the mouse hippocampus. Learn. Mem. 4: 230-243.

Ohanna, M., Sobering, A.K., Lapointe, T., Lorenzo, L., Praud, C., Petroulakis, E., Sonenberg, N., Kelly, P.A., Sotiropoulos, A., and Pende, M. 2005. Atrophy of S6K1 $1^{-1-}$ skeletal muscle cells reveals distinct mTOR effectors for cell cycle and size control. Nat. Cell Biol. 7: 286-294.

O'Keefe, J. 1993. Hippocampus, theta, and spatial memory. Curr. Opin. Neurobiol. 3: 917-924.

O'Keefe, J. and Dostrovsky, J. 1971. The hippocampus as a spatial map Preliminary evidence from unit activity in the freely moving rat. Brain Res. 34: 171-175.

Page, G., Khidir, F.A., Pain, S., Barrier, L., Fauconneau, B., Guillard, O., Piriou, A., and Hugon, J. 2006. Group I metabotropic glutamate receptors activate the p70S6 kinase via both mammalian target of rapamycin (mTOR) and extracellular signal-regulated kinase (ERK $1 / 2$ ) signaling pathways in rat striatal and hippocampal synaptoneurosomes. Neurochem. Int. 49: 413-421.

Park, I.H., Bachmann, R., Shirazi, H., and Chen, J. 2002. Regulation of ribosomal S6 kinase 2 by mammalian target of rapamycin. J. Biol. Chem. 277: 31423-31429.

Parsons, R.G., Gafford, G.M., and Helmstetter, F.J. 2006. Translational control via the mammalian target of rapamycin pathway is critical for the formation and stability of long-term fear memory in amygdala neurons. J. Neurosci. 26: 12977-12983.

Pende, M., Um, S.H., Mieulet, V., Sticker, M., Goss, V.L., Mestan, J., Mueller, M., Fumagalli, S., Kozma, S.C., and Thomas, G. 2004. S6K1 ${ }^{-1}-/$ S6K2 $2^{-1-}$ mice exhibit perinatal lethality and rapamycin-sensitive 5 '-terminal oligopyrimidine mRNA translation and reveal a mitogen-activated protein kinase-dependent S6 kinase pathway. Mol. Cell. Biol. 24: 3112-3124.

Radimerski, T., Montagne, J., Hemmings-Mieszczak, M., and Thomas, G. 2002a. Lethality of Drosophila lacking TSC tumor suppressor function rescued by reducing dS6K signaling. Genes \& Dev. 16: $2627-2632$.

Radimerski, T., Montagne, J., Rintelen, F., Stocker, H., van der Kaay, J., Downes, C.P., Hafen, E., and Thomas, G. 2002b. dS6K-regulated cell growth is $\mathrm{dPKB} / \mathrm{dPI}(3) \mathrm{K}$-independent, but requires dPDK1. Nat. Cell Biol. 4: 251-255.

Raught, B., Peiretti, F., Gingras, A.C., Livingstone, M., Shahbazian, D. Mayeur, G.L., Polakiewicz, R.D., Sonenberg, N., and Hershey, J.W. 2004. Phosphorylation of eucaryotic translation initiation factor $4 \mathrm{~B}$ Ser422 is modulated by S6 kinases. EMBO J. 23: 1761-1769.

Raymond, C.R., Redmond, S.J., and Crouch, M.F. 2002. The phosphoinositide 3-kinase and p70 S6 kinase regulate long-term potentiation in hippocampal neurons. Neuroscience 109: 531-536.

Richardson, C.J., Broenstrup, M., Fingar, D.C., Julich, K., Ballif, B.A., Gygi, S., and Blenis, J. 2004. SKAR is a specific target of S6 kinase 1 in cell growth control. Curr. Biol. 14: 1540-1549.

Rosenblum, K., Meiri, N., and Dudai, Y. 1993. Taste memory: The role of protein synthesis in gustatory cortex. Behav. Neural Biol.

59: 49-56.

Roux, P.P., Shahbazian, D., Vu, H., Holz, M.K., Cohen, M.S., Taunton, J.,
Sonenberg, N., and Blenis, J. 2007. RAS/ERK signaling promotes site-specific ribosomal protein S6 phosphorylation via RSK and stimulates cap-dependent translation. J. Biol. Chem. 282: $14056-14064$

Ruvinsky, I. and Meyuhas, O. 2006. Ribosomal protein S6 phosphorylation: From protein synthesis to cell size. Trends Biochem. Sci. 31: 342-348.

Ruvinsky, I., Sharon, N., Lerer, T., Cohen, H., Stolovich-Rain, M., Nir, T., Dor, Y., Zisman, P., and Meyuhas, O. 2005. Ribosomal protein S6 phosphorylation is a determinant of cell size and glucose homeostasis. Genes \& Dev. 19: 2199-2211.

Sanna, P.P., Cammalleri, M., Berton, F., Simpson, C., Lutjens, R., Bloom, F.E., and Francesconi, W. 2002. Phosphatidylinositol 3-kinase is required for the expression but not for the induction or the maintenance of long-term potentiation in the hippocampal CA1 region. J. Neurosci. 22: 3359-3365.

Selcher, J.C., Atkins, C.M., Trzaskos, J.M., Paylor, R., and Sweatt, J.D. 1999. A necessity for MAP kinase activation in mammalian spatial learning. Learn. Mem. 6: 478-490.

Shima, H., Pende, M., Chen, Y., Fumagalli, S., Thomas, G., and Kozma S.C. 1998. Disruption of the $\mathrm{p} 70^{\mathrm{s} 6 \mathrm{k}} / \mathrm{p} 85^{\mathrm{s} 6 \mathrm{k}}$ gene reveals a small mouse phenotype and a new functional $\mathrm{S} 6$ kinase. EMBO J. 17: 6649-6659.

Soderling, T.R. and Derkach, V.A. 2000. Postsynaptic protein phosphorylation and LTP. Trends Neurosci. 23: 75-80.

Tang, S.J., Reis, G., Kang, H., Gingras, A.C., Sonenberg, N., and Schuman, E.M. 2002. A rapamycin-sensitive signaling pathway contributes to long-term synaptic plasticity in the hippocampus. Proc. Natl. Acad. Sci. 99: 467-472.

Townsend, M., Mehta, T., and Selkoe, D.J. 2007. Soluble A $\beta$ inhibits specific signal transduction cascades common to the insulin receptor pathway. J. Biol. Chem. doi: 10.1074/jbc.M610390200.

Tsokas, P., Grace, E.A., Chan, P., Ma, T., Sealfon, S.C., Iyengar, R., Landau, E.M., and Blitzer, R.D. 2005. Local protein synthesis mediates a rapid increase in dendritic elongation factor $1 \mathrm{~A}$ after induction of late long-term potentiation. J. Neurosci. 25: 5833-5843.

Tsokas, P., Ma, T., Iyengar, R., Landau, E.M., and Blitzer, R.D. 2007. Mitogen-activated protein kinase upregulates the dendritic translation machinery in long-term potentiation by controlling the mammalian target of rapamycin pathway. J. Neurosci. 27: 5885-5894.

Um, S.H., Frigerio, F., Watanabe, M., Picard, F., Joaquin, M., Sticker, M., Fumagalli, S., Allegrini, P.R., Kozma, S.C., Auwerx, J., et al. 2004. Absence of S6K1 protects against age- and diet-induced obesity while enhancing insulin sensitivity. Nature 431: 200-205.

Um, S.H., D'Alessio, D., and Thomas, G. 2006. Nutrient overload, insulin resistance, and ribosomal protein S6 kinase 1, S6K1. Cell Metab. 3: 393-402.

Wang, X., Li, W., Williams, M., Terada, N., Alessi, D.R., and Proud, C.G. 2001. Regulation of elongation factor 2 kinase by p90(RSK1) and p70 S6 kinase. EMBO J. 20: 4370-4379.

Received June 5, 2007; accepted in revised form November 1, 2007 


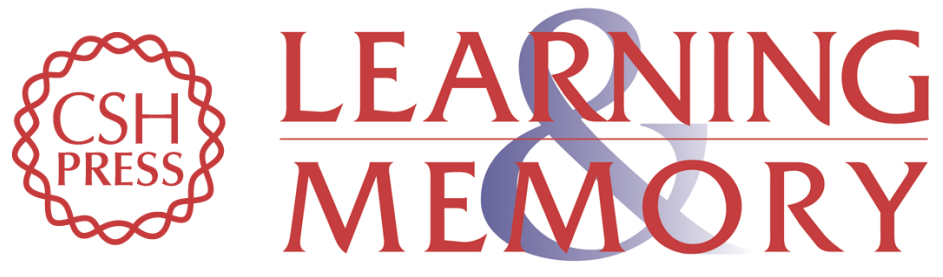

\section{Removal of S6K1 and S6K2 leads to divergent alterations in learning, memory, and synaptic plasticity}

Marcia D. Antion, Maayan Merhav, Charles A. Hoeffer, et al.

Learn. Mem. 2008, 15:

Access the most recent version at doi:10.1101//m.661908

References This article cites 61 articles, 28 of which can be accessed free at: http://learnmem.cshlp.org/content/15/1/29.full.html\#ref-list-1

License

Email Alerting Receive free email alerts when new articles cite this article - sign up in the box at the Service top right corner of the article or click here. 